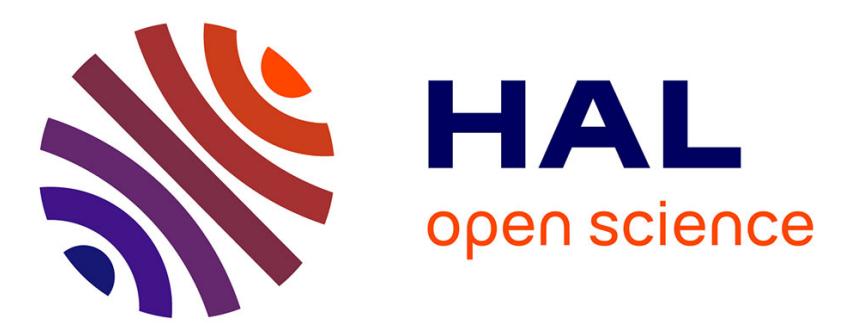

\title{
Antimicrobial susceptibility testing of historical and recent clinical isolates of in the United Kingdom using the Etest method
}

\author{
N. K. Fry, J. Duncan, L. Vaghji, R. C. George, T. G. Harrison
}

\section{- To cite this version:}

N. K. Fry, J. Duncan, L. Vaghji, R. C. George, T. G. Harrison. Antimicrobial susceptibility testing of historical and recent clinical isolates of in the United Kingdom using the Etest method. European Journal of Clinical Microbiology and Infectious Diseases, 2010, 29 (9), pp.1183-1185. 10.1007/s10096010-0976-1 . hal-00597960

\section{HAL Id: hal-00597960 \\ https://hal.science/hal-00597960}

Submitted on 3 Jun 2011

HAL is a multi-disciplinary open access archive for the deposit and dissemination of scientific research documents, whether they are published or not. The documents may come from teaching and research institutions in France or abroad, or from public or private research centers.
L'archive ouverte pluridisciplinaire HAL, est destinée au dépôt et à la diffusion de documents scientifiques de niveau recherche, publiés ou non, émanant des établissements d'enseignement et de recherche français ou étrangers, des laboratoires publics ou privés. 
Diseases

Editorial Manager(tm) for European Journal of Clinical Microbiology \& Infectious

$$
\text { Manuscript Draft }
$$

Manuscript Number: EJCMID-D-10-00262R1

Title: Antimicrobial susceptibility testing of historical and recent clinical isolates of Bordetella pertussis in the United Kingdom using the Etest method

Article Type: Brief Report

Keywords: Bordetella pertussis; antimicrobial resistance; antimicrobial susceptibility; Etest

Corresponding Author: Dr Norman Kenneth Fry, Ph.D.

Corresponding Author's Institution: Health Protection Agency Centre for Infections

First Author: Norman K Fry, BSc, PhD

Order of Authors: Norman K Fry, BSc, PhD; John Duncan, BSc, MSc; Lalita Vaghji, BSc; Robert C George, M.D.; Timothy G Harrison, BSc, PhD

Abstract: Reports of the development of antimicrobial resistance by Bordetella pertussis to macrolides in the United States and Taiwan, together with a recent increase in pertussis notifications and laboratory confirmed cases in England and Wales in 2008, prompted the examination of historical and recent clinical isolates from patients for evidence of such resistance in our collection. Isolates

submitted to our laboratory as part of the enhanced surveillance scheme for pertussis, from 2001 to 2009, were tested against three agents, erythromycin, clarithromycin and azithromycin, by the Etest (bioMérieux) method. All isolates $(\mathrm{n}=583)$ were fully susceptible to all three agents tested (Minimum Inhibitory Concentrations, $\leq 0.125 \mu \mathrm{g} / \mathrm{ml}$ ). All but one strain $(582 / 583)$ had MICs of $\leq 0.064$ for all three agents. The control strain of B. pertussis A228 (from Centers for Disease Control and Prevention, USA) with a resistant phenotype had an MIC of $>256 \mu \mathrm{g} / \mathrm{ml}$. Although no evidence of resistance was found in the strains tested from the United Kingdom, screening for antimicrobial resistance of B. pertussis may be warranted in cases that are unresponsive to macrolide treatment and to provide early warning of such emergence in the future. 


\section{Response to Reviewer 1}

This approach, which includes isolates with different serotypes, from different age groups, from geographically diverse locations within UK, and distinct genotypic types would be adequate for surveillance purposes, but taking into account that occurrence of B. pertussis resistance to macrolides is estimated to be low, the recommendation would be that a given $\mathrm{B}$. pertussis isolate should be tested for resistance only if there is therapeutic failure.

Authors response: This is indeed what we have stated 'sensitivity testing for B. pertussis may be warranted in cases that are unresponsive to macrolide treatment "

But we believe that the additional clause 'and to provide early warning of for emergence of such resistance of in the future.' Is fully warranted.

In addition we would argue that evidence showing that B.pertussis isolates are sensitive to macrolides is still noteworthy in order to prevent the over-reporting of the occurrence of resistance. Certainly these data have not been previously reported for the UK, however, to accommodate this reviewer's view we have re-formatted the manuscript to a brief report, but would argue that a medical microbiology journal is the most appropriate.

Response to Reviewer 2

This study should be published. It confirms that macrolides are still antibiotics of choice for pertussis infection. The methodology is correct; data are clear and well presented.

Authors reposnse: We thank this reviewer for these positive comments.

Why are the authors using glycerol? The consensus technique was published by Mooi et al., Eur. J. Clin. Microbiol. Infect. Dis. 2000. The chromosome of B. pertussis being dynamic and containing many IS, glycerol might induce rearrangements.

Authors response: The use of glycerol as a cryoprotectant for preservation of suspensions of microorganisms at low temperature is well-established and is widely used in both commercial and in-house preparations. Our cultures are held at $-80^{\circ} \mathrm{C}$ so these are effectively inert. Strains tested for genotypic markers such as pertactin, pertussis toxin and MLVA type before and after storage show no difference. The mechanism for possible induction of rearrangements of the B.pertussis genome due to glycerol is not clear and in the absence of evidence to this effect we cannot comment further. We note that the method suggested by the reviewer uses saccharose, but we are not aware of any data comparing different preservation media on the pertussis genome and any effects of genome rearrangement. 


\section{Antimicrobial susceptibility testing of historical and recent clinical}

3 isolates of Bordetella pertussis in the United Kingdom using the

4 Etest method

\section{$5 \quad$ N. K. Fry · J. Duncan · L. Vaghji $\cdot$ R. C. George · T. G. Harrison}

6 Abstract Reports of the development of antimicrobial resistance by Bordetella pertussis to

7 macrolides in the United States and Taiwan, together with a recent increase in pertussis

8 notifications and laboratory confirmed cases in England and Wales in 2008, prompted the

9 examination of historical and recent clinical isolates from patients for evidence of such resistance in our collection. Isolates submitted to our laboratory as part of the enhanced surveillance scheme for pertussis, from 2001 to 2009, were tested against three agents, erythromycin, clarithromycin and azithromycin, by the Etest (bioMérieux) method. All isolates ( $n=583$ ) were fully susceptible to all three agents tested (Minimum Inhibitory Concentrations, $\leq 0.125 \mu \mathrm{g} / \mathrm{ml})$. All but one strain $(582 / 583)$ had MICs of $\leq 0.064$ for all three agents. The control strain of B. pertussis A228 (from Centers for Disease Control and Prevention, USA) with a resistant phenotype had an MIC of $>256 \mu \mathrm{g} / \mathrm{ml}$. Although no evidence of resistance was found in the strains tested from the United Kingdom, screening for antimicrobial resistance of $B$. pertussis may be warranted in cases that are unresponsive to macrolide treatment and to provide early warning of such emergence in the future.

Key words: Bordetella pertussis, antimicrobial resistance, antimicrobial susceptibility, Etest

N. K. Fry $(\bowtie) \cdot$ J. Duncan · L. Vaghji $\cdot$ R. C. George $\cdot$ T. G. Harrison

Respiratory and Systemic Infection Laboratory, Health Protection Agency Centre for Infections, 61 Colindale Avenue, London NW9 5EQ, United Kingdom e-mail: Norman.Fry@HPA.org.uk 
1 Susceptibility testing of Bordetella spp. including B. pertussis clinical isolates is not routinely

2 performed and prior to 1994 resistance to erythromycin in B. pertussis had not been

3 observed [1]. However, since then there have been a few reports presenting the emergence of erythromycin-resistant $B$. pertussis isolates in the USA $[2,3]$ and one in Taiwan [4].

These reports and a recent increase in notifications [5], prompted this examination of our collection of historical and recent clinical isolates of $B$. pertussis. Clinical isolates of $B$. pertussis are submitted to our laboratory, the Respiratory and Systemic Infection Laboratory (RSIL) as part of the enhanced surveillance scheme for pertussis for England and Wales. Our laboratory also receives isolates from Ireland, Northern Ireland and Scotland, and these were also included in this analysis. In this study, we report the susceptibility testing to erythromycin, clarithromycin and azithromycin by the Etest (bioMérieux) method for $583 B$. pertussis clinical isolates that represent the majority ( $\geq 95 \%$ ) of isolates submitted to the RSIL between January 2004 and December 2009, and a selected number of isolates from September 2001 to December 2003. The years of isolation and numbers of strains isolated were as follows: 2001, 2; 2002, 40; 2003, 17; 2004, 68; 2005, 110; 2006, 53; 2007, 69; 2008, 134; and 2009, 90. Prior to testing isolates were initially subcultured into Charcoal blood agar (Media Services, Central Public Health Laboratory, London) to check for purity and incubated at $37^{\circ} \mathrm{C}$ for $24-72 \mathrm{hrs}$. Mueller Hinton agar plates supplemented with $10 \%$ horse blood (Oxoid, CPHL Media Services), $25 \mathrm{ml}$ final volume, $90 \mathrm{~mm}$ triple-vented Petri dish (Greiner Bio-One Ltd), were inoculated by resuspension of bacterial growth as recommended for Bordetella spp. testing, but modified to use a higher MacFarland equivalent of 8 , to achieve the semi-confluent growth required. E-strips (bioMérieux) were equilibrated to room temperature then carefully applied to the centre of each agar plate. Inoculated plates were incubated for $48 \mathrm{~h}$ to 7 days in a moist atmosphere at $37^{\circ} \mathrm{C}$. The minimum inhibitory concentrations (MICs) were determined by using the Etest methodology. The following compounds were tested erythromycin (Cat. No. 1058), clarithromycin (Cat. No. 0878), and azithromycin (Cat. No. 0168). Control strains of erythromycin resistant B. pertussis A228 (a gift from Garry Sanden, Centers for Disease Control and Prevention, Atlanta, Georgia, USA) and the Oxford Staphlyloccus aureus NCTC6571 (National Collection of Type Cultures, London) were included in each batch. 
1 The MIC values of test and control strains of $B$. pertussis were recorded at $72 \mathrm{~h}$, following

2 the manufacturer's instructions. In addition the plates were examined at 7 days to check for

3 the appearance of the heterogenous phenotype for erythromycin resistance [6]. Isolates of

4 B. pertussis with MICs of $>256 \mu \mathrm{g} / \mathrm{ml}$ after $72 \mathrm{~h}$ were considered be resistant [2].

5 The B. pertussis isolates tested (from 2001-2009) included different serotypes (11 serotype

61,$2 ; 569$ serotype 1,3; and 11 untypable) from different age groups (<3 month, 348; 3-5

7 months, 90; 6-11 months, $23 ; 1-4$ years, $1 ; 5-9$ years, $5 ; 10-14$ years, $10 ; \geq 15$ years, 15;

8 unknown, 24) with a male:female ratio of 1:1.1. Isolates were received from geographically

9 diverse locations within the United Kingdom and were known to include a number of 10 distinct genotypic types, i.e., pertactin, pertussis toxin, Multi-locus Variable Number of 11 Tandem Repeats Analysis [7], and authors' unpublished data. All isolates (523/523) were

susceptible to all three agents tested (MICs $\leq 0.125 \mu \mathrm{g} / \mathrm{ml}$ ) with the Etest method. An example of the results obtained is shown in the Figure. All isolates had MICs of $\leq 0.064 \mu \mathrm{g} / \mathrm{ml}$ with both erythromycin and azithromycin and one strain had an MIC of $0.125 \mu \mathrm{g} / \mathrm{ml}$ with clarithromycin. These results are comparable to those obtained with these agents by a study of 36 strains from Northern California by the Etest method [8]. No evidence of heterogeneous resistance was found. The erythromycin resistant $B$. pertussis A228 strain always yielded an MIC value of $>256 \mu \mathrm{g} / \mathrm{ml}$ with all three agents, which is consistent with that previously reported [2]. The control strain NCTC6571 gave results consistent with target MICs for all three of these agents i.e., $0.12 \mu \mathrm{g} / \mathrm{ml}[9]$.

Macrolides (especially erythromycin) remain the current antibiotics of choice for postexposure prophylaxis and treatment of pertussis infection [10]. Azithromycin is also recommended for prophylaxis of neonates as it is associated with fewer adverse effects [11]. The data from this study confirm that the current guidelines for macrolide treatment remain appropriate for $B$. pertusiss [11-13]. There are few documented occurrences of $B$. pertussis resistance to macrolides to date and the frequency of occurrence is estimated to be low $(<1 \%)$ [6]. Although no evidence of macrolide resistance was found in this study of a large ( $n=583$ ) number of clinical isolates from the UK, sensitivity testing for $B$. pertussis may be warranted in cases that are unresponsive to macrolide treatment and to provide early warning of for emergence of such resistance of in the future. The mechanism of resistance 


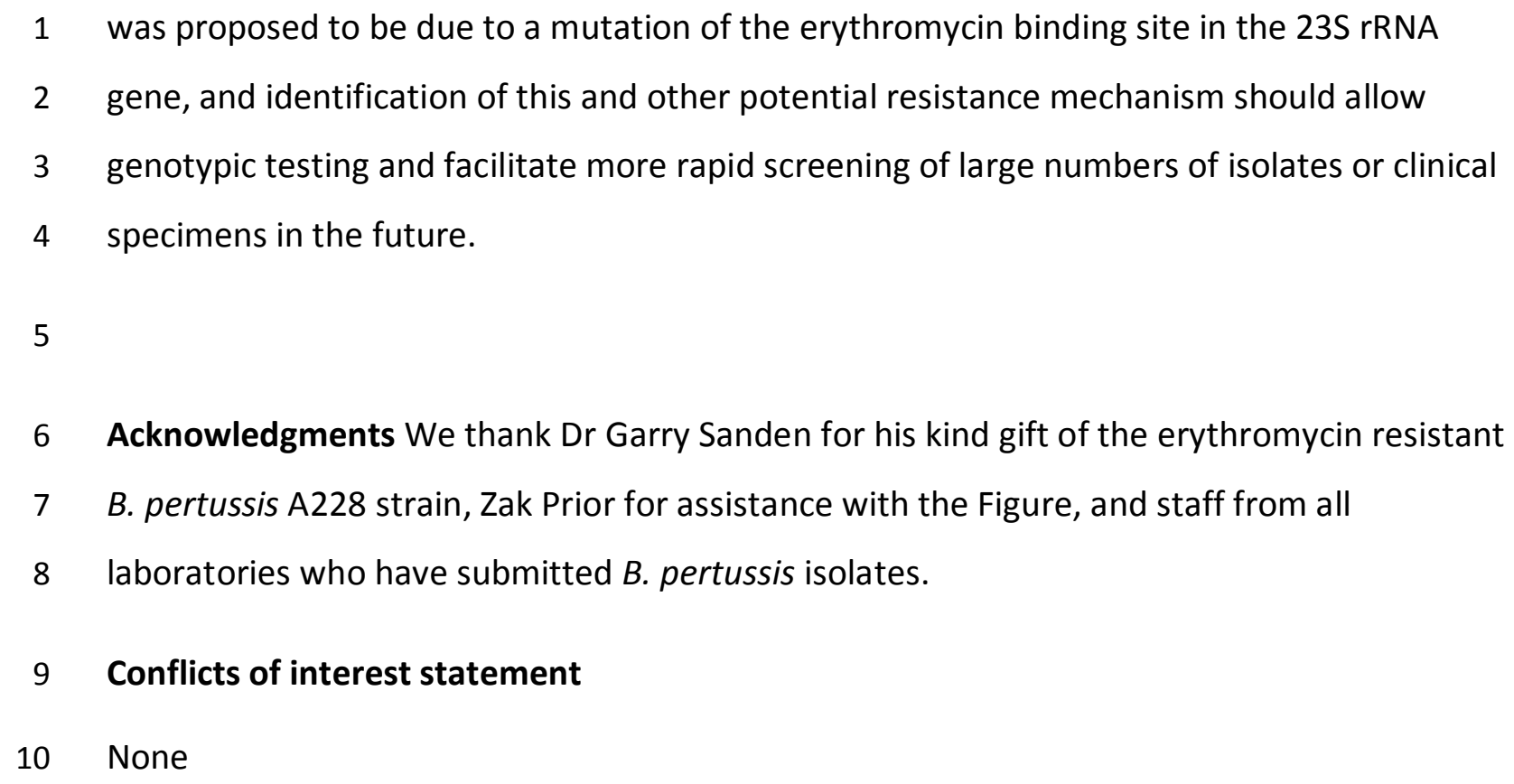


1. Lewis K, Saubolle MA, Tenover FC, Rudinsky MF, Barbour SD, Cherry JD (1995) Pertussis caused by an erythromycin-resistant strain of Bordetella pertussis. Pediatr Infect Dis J 14:388-391

2. Bartkus JM, Juni BA, Ehresmann K, Miller CA, Sanden GN, Cassiday PK, Saubolle M, Lee B, Long J, Harrison AR, Besser JM (2003) Identification of a mutation associated with erythromycin resistance in Bordetella pertussis: implications for surveillance of antimicrobial resistance. J Clin Microbiol 41:1167-1172

3. Korgenski EK, Daly JA (1997) Surveillance and detection of erythromycin resistance in Bordetella pertussis isolates recovered from a pediatric population in the intermountain west region of the United States. J Clin Microbiol 35:2989-2991

4. Yao S-M, Liaw G-J, Chen Y-Y, Yen M-H, Chen Y-H, Mu J-J, Chiang CS (2008) Antimicrobial susceptibility testing of Bordetella pertussis in Taiwan prompted by a case of pertussis in a paediatric patient. J Med Microbiol 57:1577-1580

5. HPA (2009). Statutory Notifications of Infectious Diseases (NOIDs) - Annual Totals 1994 to 2008 - England and Wales. Health Protection Agency, London. http://www.hpa.org.uk/web/HPAwebFile/HPAweb_C/1251473364307. Accessed 1 April 2010

6. Wilson KE, Cassiday PK, Popovic T, Sanden GN (2002) Bordetella pertussis isolates with a heterogeneous phenotype for erythromycin resistance. J Clin Microbiol 40:2942-2944

7. Litt DJ, Neal SE, Fry, NK (2009) Changes in genetic diversity of the UK Bordetella pertussis population between 1920 and 2006 reflect vaccination coverage and the emergence of a single dominant clonal type. J Clin Microbiol 47:680-688

8. Gordon KA, Fusco J, Biedenbach DJ, Pfaller MA, Jones RN (2001) Antimicrobial susceptibility testing of clinical isolates of Bordetella pertussis from northern California: report from the SENTRY antimicrobial surveillance program. Antimicrob Agents Chemother 45:3599-3600

9. Andrews JM (2010) BSAC Methods for Antimicrobial Susceptibility Testing. http://www.bsac.org.uk/_db/_documents/Version_9.1_March_2010_final.pdf. Accessed 1 April 2009

10. Murphy TV, Slade BA, Broder KR, Kretsinger K, Tiwari T, Joyce PM, Iskander JK, Brown $K$, Moran JS (2008) Prevention of pertussis, tetanus, and diphtheria among pregnant and postpartum women and their infants: recommendations of the Advisory Committee on Immunization Practices (ACIP). MMWR Recomm Rep 57:1-47, 51. http://www.cdc.gov/mmwr/preview/mmwrhtml/rr5704a1.htm. Accessed 1 April $\underline{2010}$ 
11. Tiwari T, Murphy TV, Moran J (2005) Recommended antimicrobial agents for the treatment and postexposure prophylaxis of pertussis: 2005 CDC Guidelines. MMWR Recomm Rep 54:1-16

12. Gonzales R, Bartlett JG, Besser RE, Cooper RJ, Hickner JM, Hoffman JR, Sande MA (2001) Principles of appropriate antibiotic use for treatment of uncomplicated acute bronchitis: background. Ann Intern Med 134:521-529

13. Dodhia H, Crowcroft NS, Bramley JC, Miller E (2002) UK guidlines for use of erythromycin chemoprophylaxis in persons exposed to pertussis. J Public Health Med 24:200-206 
1

2

3

4

5

6

7

8

9

10

1 Figure. Example of results from a UK clinical B. pertussis strain subcultured on Mueller

2 Hinton agar plate supplemented with $10 \%$ horse blood challenged with the erythromycin

3 Etest strip after $72 \mathrm{~h}$ incubation, showing zone of clearance.

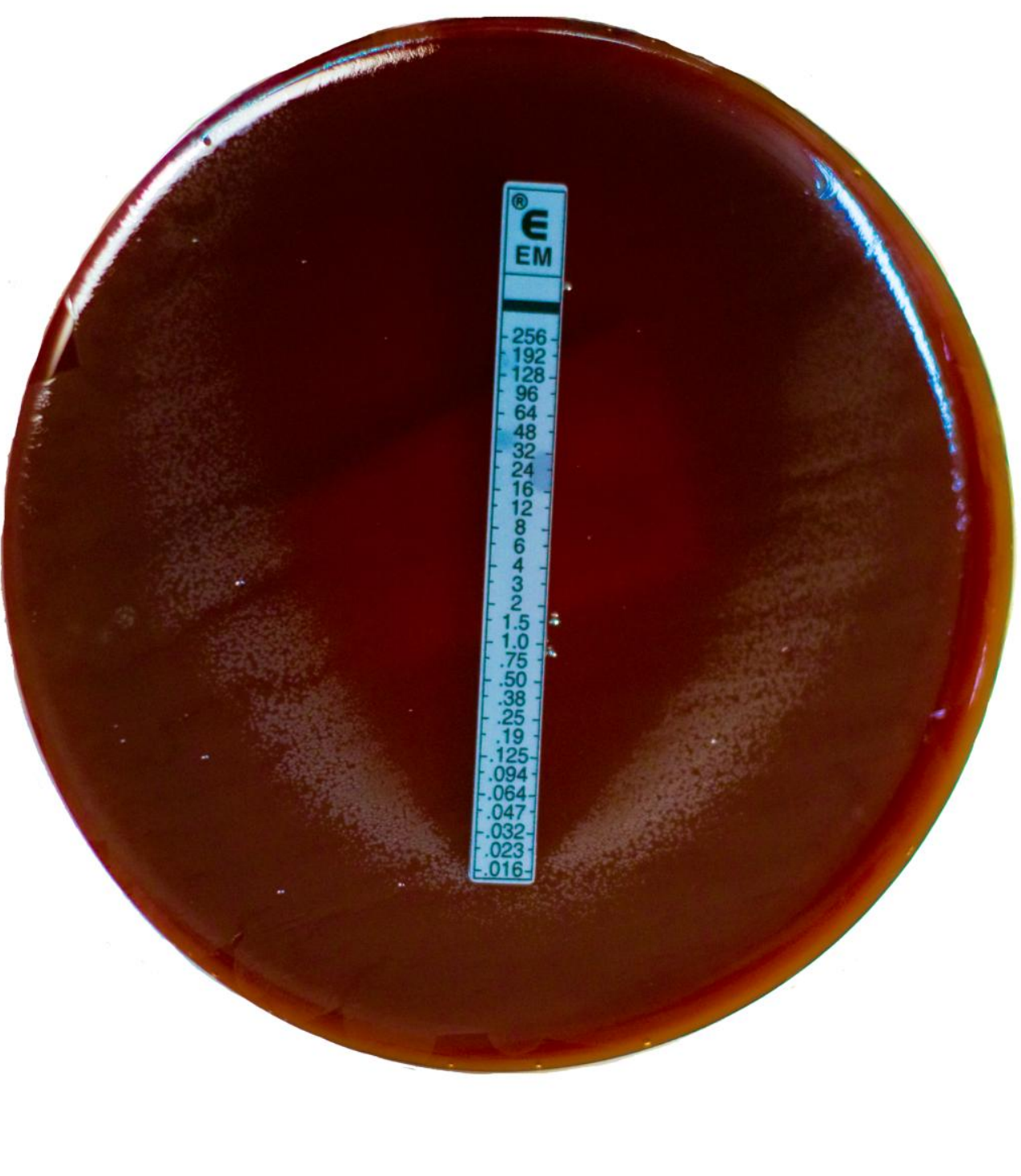

